\title{
Thermal Vacuum Testing of a Proto-flight Miniature Loop Heat Pipe with Two Evaporators and Two Condensers
}

\author{
Jentung $\mathrm{Ku}^{1}$, Laura Ottenstein ${ }^{2}$ \\ NASA Goddard Space Flight Center ${ }^{1}$ \\ Greenbelt, Maryland 20771
}

This paper describes thermal vacuum testing of a proto-flight miniature loop heat pipe (MLHP) with two evaporators and two condensers designed for future small systems applications requiring low mass, low power and compactness. Each evaporator contains a wick with an outer diameter of $6.35 \mathrm{~mm}$, and each has its own integral compensation chamber (CC). Miniaturization of the loop components reduces the volume and mass of the thermal system. Multiple evaporators provide flexibility for placement of instruments that need to be maintained at the same temperature, and facilitate heat load sharing among instruments, reducing the auxiliary heater power requirement. A flow regulator is used to regulate heat dissipations between the two condensers, allowing flexible placement of radiators on the spacecraft. A thermoelectric converter (TEC) is attached to each CC for control of the operating temperature and enhancement of start-up success. Tests performed include start-up, power cycle, sink temperature cycle, high power and low power operation, heat load sharing, and operating temperature control. The proto-flight MLHP demonstrated excellent performance in the thermal vacuum test. The loop started successfully and operated stably under various evaporator heat loads and condenser sink temperatures. The TECs were able to maintain the loop operating temperature within $\pm 1 \mathrm{~K}$ of the desired set point temperature at all power levels and all sink temperatures. The un-powered evaporator would automatically share heat from the other powered evaporator. The flow regulator was able to regulate the heat dissipation among the radiators and prevent vapor from flowing into the liquid line.

\section{Nomenclature/Acronym}

$\begin{array}{ll}\text { C1 } & =\text { condenser } 1 \\ \text { C2 } & =\text { condenser } 2 \\ \text { CC } & =\text { compensation chamber } \\ \text { CC1 } & =\text { compensation chamber } 1 \\ \text { CC2 } & =\text { compensation chamber } 2 \\ \text { E1 } & =\text { evaporator } 1 \\ \text { E2 } & =\text { evaporator } 2 \\ \text { E4 } & =\text { evaporator } 4 \\ \text { LHP } & =\text { loop heat pipe } \\ \text { MLHP } & =\text { miniature loop heat pipe } \\ \text { TEC } & =\text { thermoelectric converter } \\ \text { TEC1 } & =\text { thermoelectric converter } 1 \\ \text { TEC2 } & =\text { thermoelectric converter } 2\end{array}$

\section{Introduction}

loop heat pipe (LHP) is a very versatile heat transfer device which can transport a large heat load over a long Adistance with a small temperature difference ${ }^{1,2}$. LHPs are being used on several commercial communications satellites and NASA's ICESat, SWIFT, AURA, GOES-N and GOES-R spacecraft ${ }^{3-11}$. These LHPs have a single

${ }^{1}$ Laboratory Manager, Thermal Engineering Branch, Goddard Space Flight Center, Greenbelt, Maryland, USA, AIAA Senior Member

${ }^{2}$ Aerospace Engineer, Thermal Engineering Branch, Goddard Space Flight Center, Greenbelt, Maryland, USA 
evaporator with a 25-mm outer diameter primary wick. For small spacecraft applications, miniaturization of the LHP is necessary in order to meet the stringent requirements of low mass, low power and compactness. When the heat source has a large thermal footprint, or several heat sources need to be maintained at similar temperatures, an LHP with multiple evaporators is highly desirable. Multiple evaporators also provide an inherent heat load sharing function among several heat source components ${ }^{12}$. Under NASA's New Millennium Program Space Technology 8 (ST 8) Project, Goddard Space Flight Center (GSFC) has developed a Thermal Loop technology utilizing a miniature loop heat pipe (MLHP) with multiple evaporators and multiple condensers to transport heat, and thermoelectric converters (TECs) to control the loop operating temperature.

Figure 1 shows the Thermal Loop concept. At the heart of the Thermal Loop is an MLHP. Key features include: 1) multiple evaporators in a single LHP where each evaporator has its own integral compensation chamber (CC); 2) a primary wick with an outer diameter (O.D.) of $6.35 \mathrm{~mm}$ for each evaporator; 3) multiple condensers that are attached to different radiators; 4) a TEC assembly that is attached to each CC and connected to the evaporator via flexible thermal straps; 5) a flow regulator located downstream of the condensers; 6) coupling blocks connecting the vapor line and liquid line for heat exchange; 7) ammonia working fluid; and 8) a thermal mass that is attached to each evaporator to serve as the instrument simulator.

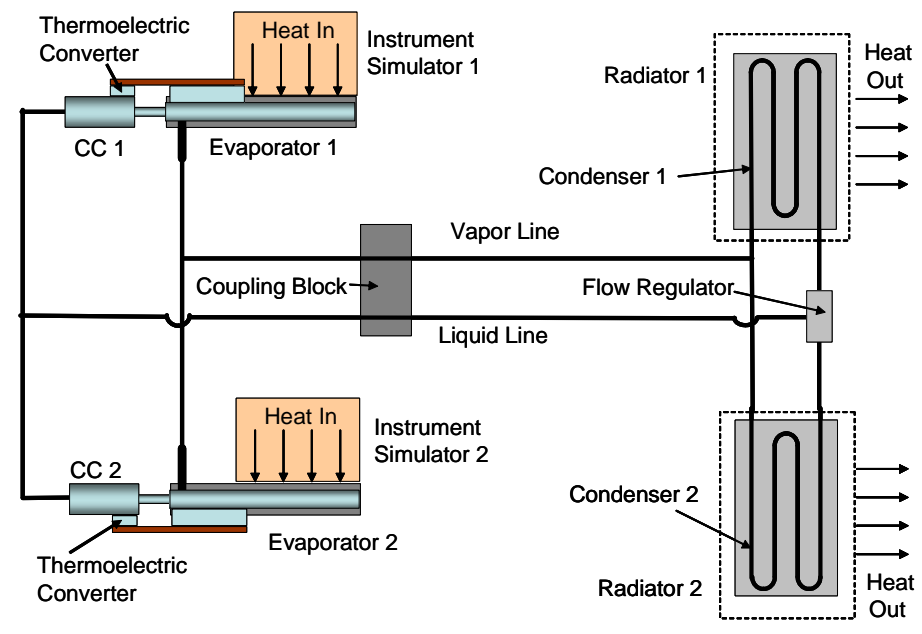

Figure 1. Thermal Loop Experiment Concept

The benefits offered by the Thermal Loop technology are: 1) Small components that make up the MLHP reduce the mass and volume of the thermal subsystem. 2) Multiple evaporators allow multiple instruments to be placed at various locations inside the spacecraft and still be maintained at the same or similar temperatures regardless of their heat dissipations. 3) The 'off" instruments can share the heat dissipated by the "on" instruments. This reduces or eliminates the auxiliary power required to maintain "off" instruments above the minimum temperature. Heat load sharing among evaporators is an inherent function of multi-evaporator LHPs and is automatically accomplished through internal vapor distribution among the evaporators. 4) Multiple radiators can be placed on various surfaces of the spacecraft and can be exposed to different thermal environments. As long as all the radiators together can dissipate the total heat load, some of the radiators can even face the sun, and the passive flow regulator at the downstream of the condensers can automatically regulate the heat dissipation among all condensers. 5) Traditional LHPs rely on cold-biasing and electrical heaters to maintain the CC at the desired set point temperature. The Thermal Loop uses TECs to provide active heating and cooling to the CC to control the LHP set point temperature ${ }^{13-15}$. The required TEC control heater power is much less than that of using electrical heaters. Active CC cooling by the TEC is particularly useful when the loop needs to re-start within a short time. 6) TECs ensure successful start-up without start-up heaters, which are usually required in traditional LHPs.

An MLHP Breadboard was built and tested in the laboratory and thermal vacuum environments and demonstrated excellent performance ${ }^{15-20}$. In addition, an analytical model was developed to simulate the steady state and transient operation of the MLHP ${ }^{21}$. Subsequently, an MLHP proto-flight unit was built for space flight validation of the Thermal Loop technology. This paper presents the design and thermal vacuum tests of the MLHP proto-flight unit. 


\section{Test Article and Test Setup}

Figure 2 shows a picture of the MLHP proto-flight unit. Major design parameters are summarized in Table 1. The MLHP proto-flight unit consisted of two parallel evaporators with integral CCs, two parallel condensers, a common vapor transport line and a common liquid return line. Each evaporator was made of aluminum 6061 with an O.D. of $9 \mathrm{~mm}$ and a length of $52 \mathrm{~mm}$. The primary wick was made of titanium with a pore radius of about $1.2 \mu \mathrm{m}$. Each CC was made of stainless steel with an O.D. of $22.2 \mathrm{~mm}$ and a length of $72.4 \mathrm{~mm}$. The vapor line, liquid line and condensers were all made of stainless steel. The vapor line had an O.D. of $2.38 \mathrm{~mm}$ and a length of 1580 $\mathrm{mm}$. The liquid line had an O.D. of 1.59 $\mathrm{mm}$ and a length of $1120 \mathrm{~mm}$. Each condenser had an O.D. of $2.38 \mathrm{~mm}$ and a length of $1676 \mathrm{~mm}$, and was serpentine and embedded in a radiator. A flow regulator consisting of capillary wicks was installed at the downstream of the two condensers. The MLHP was charged with 31.3 grams of anhydrous

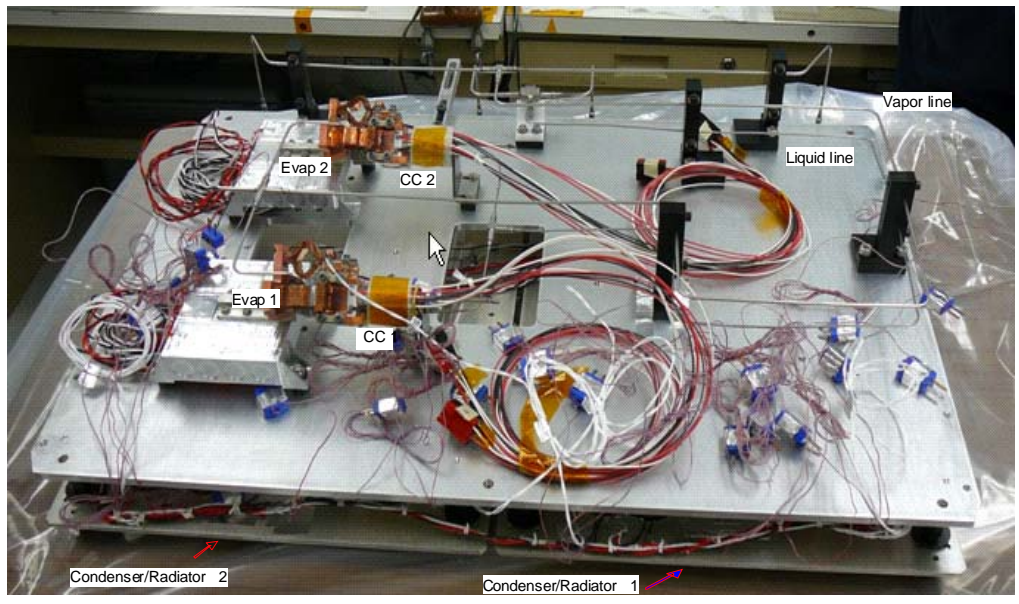

Figure 2. MLHP Proto-flight Unit ammonia.

Table 1. Design Parameters of MLHP Proto-flight Unit

\begin{tabular}{|c|c|c|}
\hline Component & Material & Value \\
\hline Evaporators (2) & Aluminum 6061 & 9 mm O.D. x 52 mm L \\
\hline Primary Wicks (2) & Titanium & $\begin{array}{l}6.35 \mathrm{~mm} \text { O.D. x } 3.2 \mathrm{~mm} \text { I.D. } \\
\text { Porosity: } 0.35 \\
\text { Hydraulic diameter of vapor groove (equivalent): } 1.27 \mathrm{~mm} \\
\text { Pore radius } 1.25 \mu \mathrm{m}(\mathrm{E} 1), 1.20 \mu \mathrm{m}(\mathrm{E} 2) \\
\text { Permeability: } 0.8 \times 10^{-14} \mathrm{~m}^{2}(\mathrm{E} 1), 1.0 \times 10^{-14} \mathrm{~m}^{2} \text { (E2) }\end{array}$ \\
\hline Secondary Wicks (2) & SS 304L & Pore radius: $45.53 \mu \mathrm{m}$ (E1), $36.04 \mu \mathrm{m}(\mathrm{E} 2)$ \\
\hline Bayonet Tubes (2) & SS 304L & $1.1 \mathrm{~mm}$ O.D. x $0.80 \mathrm{~mm}$ I.D. \\
\hline CC (2) & SS 304L & 22.5 mm O.D. x 21.2 mm I.D. x 76.7 mm L \\
\hline Vapor Line & SS 304L & $2.38 \mathrm{~mm}$ O.D. x $1.37 \mathrm{~mm}$ I.D. x $1580 \mathrm{~mm} \mathrm{~L}$ \\
\hline Liquid Line & SS 304L & 1.59 mm O.D. x 1.08 mm I.D. x 1102 mm L \\
\hline Condensers (2) & SS 304L & 2.38 mm O.D. x 1.37 mm I.D. x 1676 mm L (each) \\
\hline Flow Regulator & $\begin{array}{l}\text { SS 316L shell and } \\
\text { wicks }\end{array}$ & $\begin{array}{l}\text { Pore radius: } 9.35 \mu \mathrm{m}, 13.83 \mu \mathrm{m} \\
\text { Permeability: } 9.11 \times 10^{-13} \mathrm{~m}^{2}, 9.49 \times 10^{-13} \mathrm{~m}^{2}\end{array}$ \\
\hline Working Fluid & $\begin{array}{l}\text { Anhydrous } \\
\text { Ammonia }\end{array}$ & 31.3 grams \\
\hline
\end{tabular}

Each evaporator was made with a saddle, which could be attached to an aluminum thermal mass that simulated an instrument. The two instrument simulators (thermal masses) weighed 540 grams (attached to Evaporator 1) and 280 grams (attached to Evaporator 2), respectively. Each thermal mass had electric heaters that were wired into two circuits (top and bottom), and each circuit was powered with a variable voltage to provide a variable power of 070W. A TEC assembly consisting of two TECs made by Marlow Industries, Inc. with a model number of DT3-6, two copper straps, and a copper saddle was used between each CC and the evaporator as shown in Figure 3. Each TEC assembly was controlled by a bi-polar power supply through the MLHP Electronics Box . Changing the polarity of the applied voltage changed the TEC operation between the heating and cooling modes. Two TECs were used for redundancy. However, only one TEC was used for each CC/evaporator at any given time.

The two condensers consisted of serpentine tubes that were sandwiched between two thin aluminum plates serving as radiators. Each radiator had a surface area of $432 \mathrm{~mm}$ x $317 \mathrm{~mm}$. Each evaporator was mounted on a thermal mass, 
and the thermal masses, CCs, and transport lines were mounted on a base plate with standoffs supporting the transport lines. The base plate and the radiators were $152 \mathrm{~mm}$ apart. Three aluminum coupling blocks connecting the vapor line and liquid line were installed. Each coupling block was $20 \mathrm{~mm}$ by $20 \mathrm{~mm}$ by $6 \mathrm{~mm}$.

The MLHP proto-flight unit was placed inside a thermal vacuum chamber, as shown in Figure 4. Each radiator was cooled by a cryopanel through radation on one side (the down-facing side). Two copper cryopanels were used as radiator sinks, one for each radiator. Temperatures of the two cryopanels were set to be the same, ranging from $123 \mathrm{~K}$ to $303 \mathrm{~K}$, depending on the type of test performed, although they could be changed independently. Four supplemental heaters were installed on both radiators on the up-facing sides. These supplemental heaters were activated, when needed, to prevent the ammonia working fluid from freezing. They could be independently controlled at different set point temperatures for various tests, such as the flow regulation test. Multi-layer insulation was used between the top side of the radiator and the rest of the MLHP components (evaporators, CCs, vapor line, and liquid line and thermal masses).

More than 120 type $\mathrm{T}$ thermocouples were used to monitor the temperatures of the MLHP, radiators, and cryopanels. Figures 5 and 6 show the thermocouple locations. Note that the thermocouple numbers are not consecutive. A data acquisition system consisting of a data logger, two personal computers, and two screen monitors was used to collect, display, and store temperature and power data every second. LabView software was as used for the command and control of the test conditions.
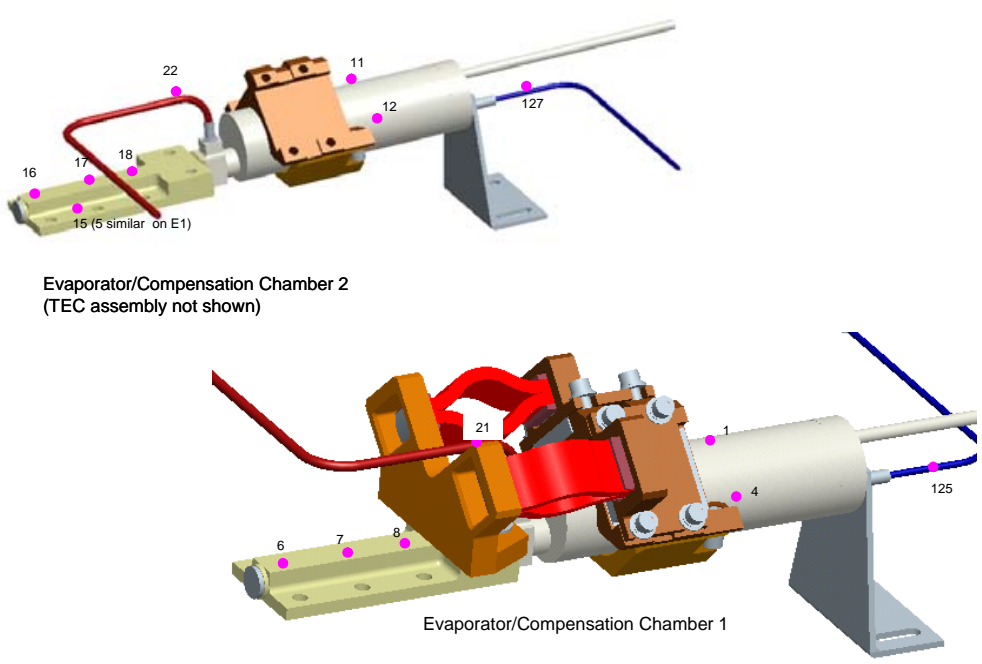

Figure 3. TEC Assemblies Connecting the CCs and Evaporators

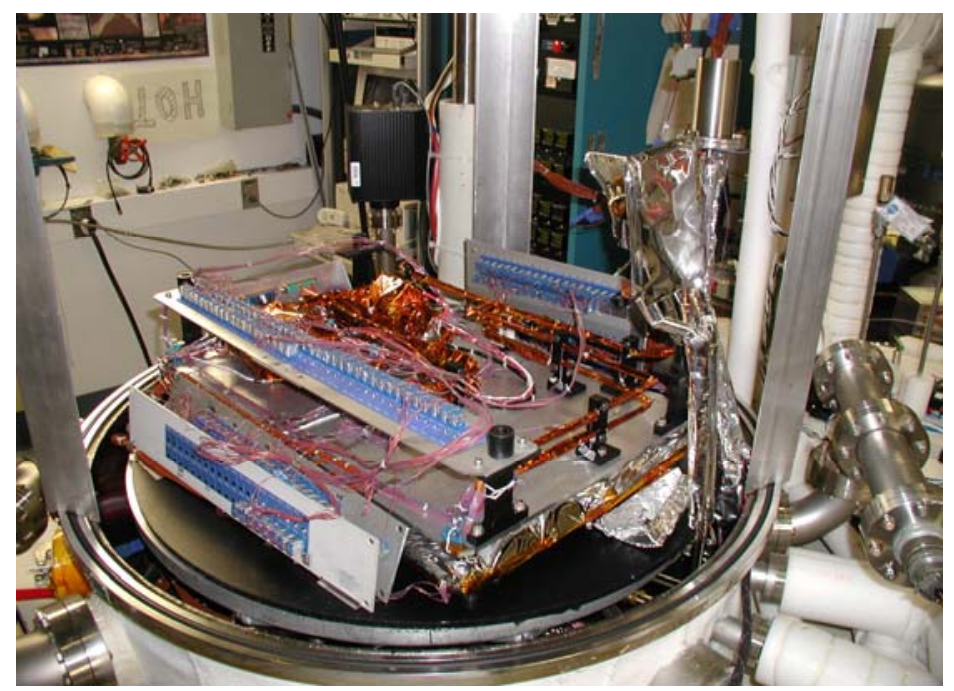

Figure 4. Picture of MLHP Protoflight Unit in the Thermal Vacuum Chamber 


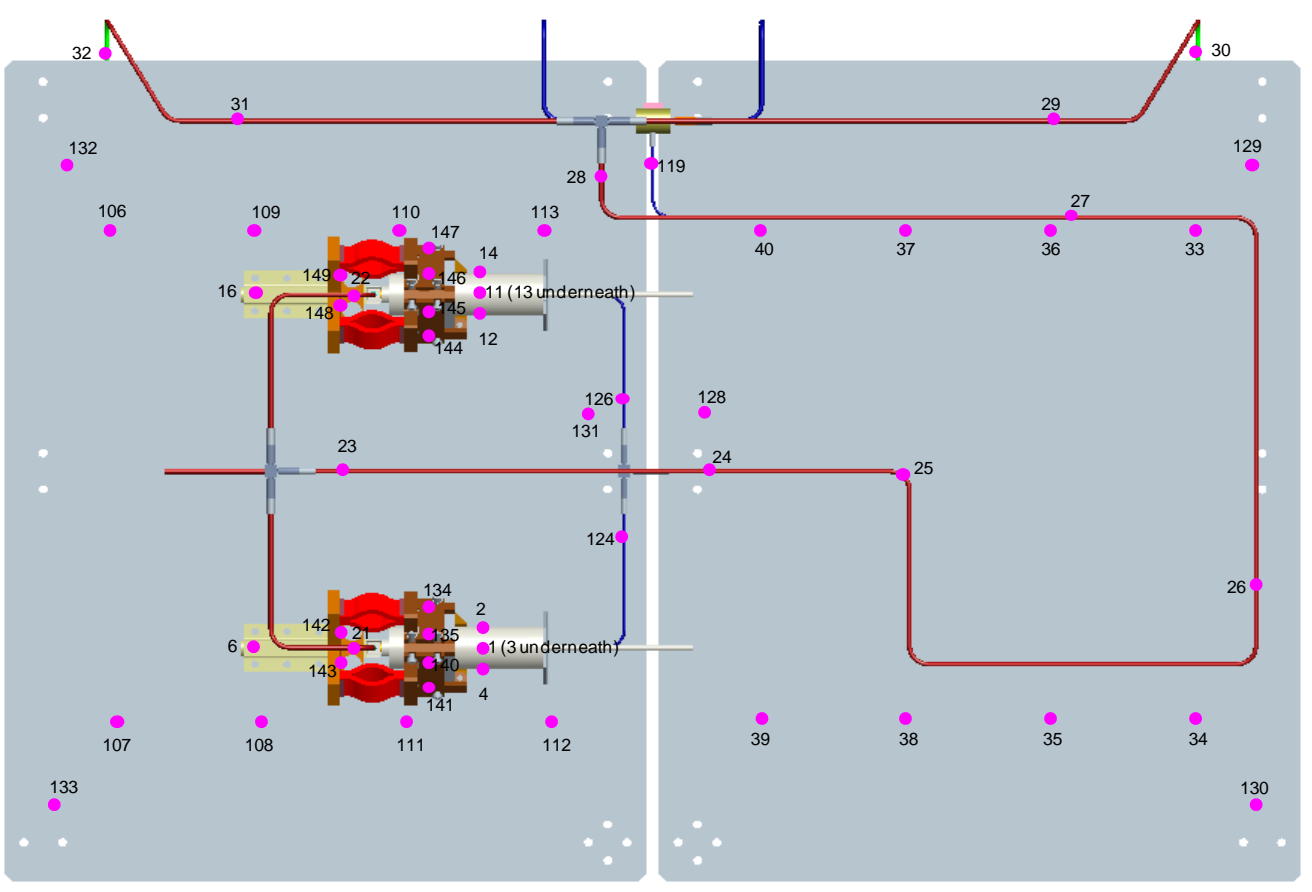

Figure 5. Thermocouple Locations (Overall) on MLHP Proto-flight in TV Testing

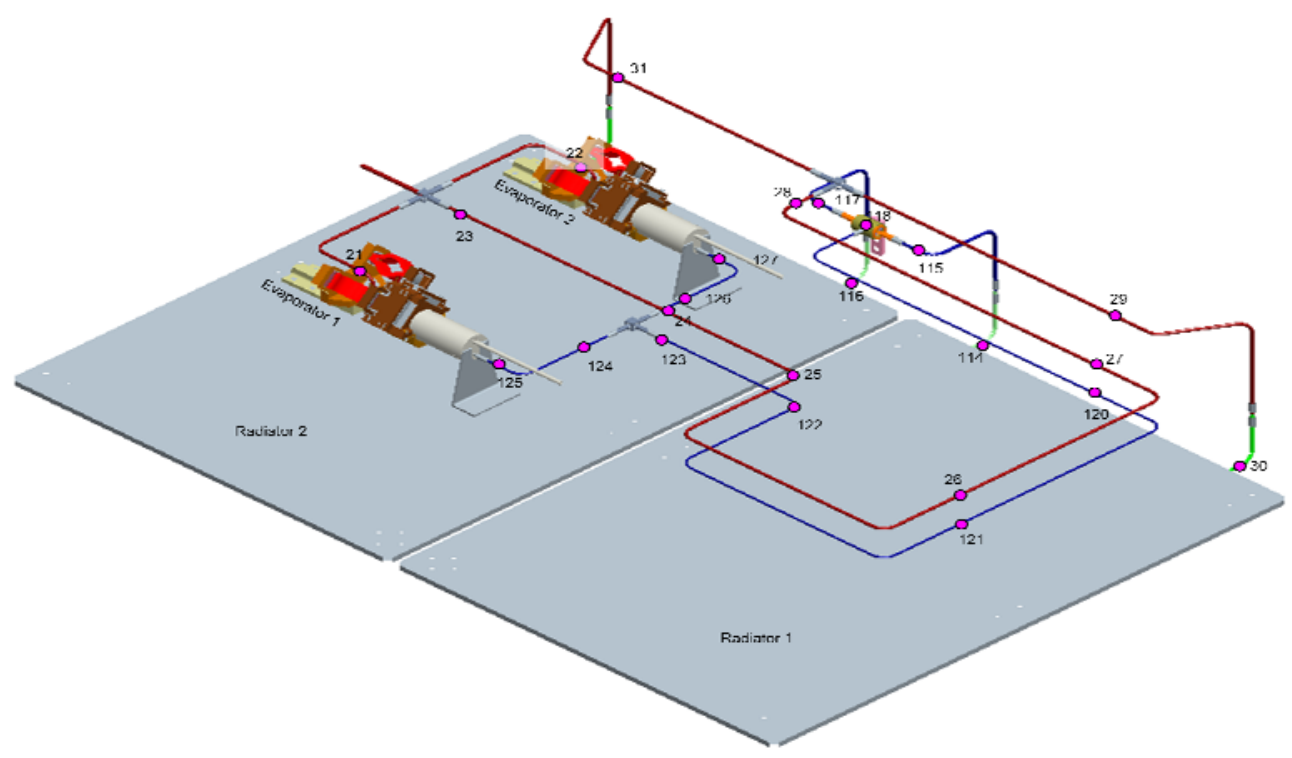

Figure 6. Thermocouple Locations on Transport Lines of MLHP Proto-flight in TV Testing 


\section{Test Results}

The NASA New millennium Program Office established a set of success criteria to be met for the MLHP proto-flight. All success criteria wet met or exceeded during the thermal vacuum test as shown in Table 2. Some test results are highlighted in the following discussions.

Table 2. Success Criteria and Validation Results for MLHP Proto-flight

\begin{tabular}{|c|c|c|c|}
\hline Test & Requirement/Success Criteria & Validation Results & Compliance \\
\hline Start-up & $\begin{array}{l}\text { - An } 80 \% \text { success rate or better } \\
\text { on a minimum of } 20 \text { start-ups } \\
\text { Demonstrate over a temperature } \\
\text { range between } 273 \mathrm{~K} \text { and } 308 \mathrm{~K}\end{array}$ & $\begin{array}{l}\text { - } 100 \% \text { success on } 43 \text { start-up tests } \\
\text { - Temperature range between } 273 \mathrm{~K} \text { and } \\
\text { 308K }\end{array}$ & $\begin{array}{l}\text { Exceed } \\
\text { requirements }\end{array}$ \\
\hline $\begin{array}{l}\text { Heat } \\
\text { Transport }\end{array}$ & - $\quad 75 \mathrm{~W}$ total heat load & - $120 \mathrm{~W}$ total heat load & $\begin{array}{l}\text { Exceed } \\
\text { requirements }\end{array}$ \\
\hline Operation & $\begin{array}{l}\text { - Control the loop saturation } \\
\text { temperature within } \pm 3 \mathrm{~K} \\
\text { between } 273 \mathrm{~K} \text { and } 308 \mathrm{~K} \\
\text { Transient operation over full } \\
\text { range of heat loads (10W to } \\
100 \mathrm{~W} \text { ) }\end{array}$ & $\begin{array}{l}\text { - Control the loop saturation temperature } \\
\text { within } \pm 1 \mathrm{~K} \text { between } 273 \mathrm{~K} \text { and } 313 \mathrm{~K} \\
\text { - Transient operation between } 5 \mathrm{~W} \text { and } \\
120 \mathrm{~W} \text { with rapid changes of heat load } \\
\text { and/or sink temperature } \\
\text { - Changed saturation temperature } \\
\text { between } 273 \mathrm{~K} \text { and } 313 \mathrm{~K} \text { while in } \\
\text { operation }\end{array}$ & $\begin{array}{l}\text { Exceed } \\
\text { requirements }\end{array}$ \\
\hline $\begin{array}{l}\text { Heat Load } \\
\text { Sharing }\end{array}$ & $\begin{array}{l}\text { - Demonstrate heat load sharing } \\
\text { between two evaporators (0W to } \\
75 \mathrm{~W})\end{array}$ & $\begin{array}{l}\text { Heat load sharing was demonstrated by } \\
\text { changing 1) heat load to one evaporator } \\
\text { (0W to } 75 \mathrm{~W}) \text {; and 2) CC saturation } \\
\text { temperature }\end{array}$ & $\begin{array}{l}\text { Exceed } \\
\text { requirements }\end{array}$ \\
\hline $\begin{array}{l}\text { LHP } \\
\text { Model } \\
\text { Correlation }\end{array}$ & $\begin{array}{l}\text { Model predictions of MLHP } \\
\text { critical temperatures within } \pm 5 \mathrm{~K} \\
\text { of the test results during steady } \\
\text { state and transient operation }\end{array}$ & $\begin{array}{l}\text { Model predictions of the loop critical } \\
\text { temperatures (CCs, evaporators, vapor } \\
\text { and liquid lines) were within } \pm 5 \mathrm{~K} \text { of the } \\
\text { test results during steady state and } \\
\text { transient operation. }\end{array}$ & $\begin{array}{l}\text { Meet } \\
\text { requirement }\end{array}$ \\
\hline
\end{tabular}

The MLHP analytical model predicted that each evaporator could transport 100W of heat. In the early phase of the test program, it was found that evaporator E2 was damaged and could transport only 60W of heat load. By contrast, evaporator E1 could transport slightly more than 100W of heat. The exact cause of the E2 damage was not known, but most likely occurred between the time when the unit was delivered to GSFC by the vendor and when the unit was being prepared for the thermal vacuum test. The schedule constraint demanded that testing of the proto-flight unit be continued with tests that did not require more than $60 \mathrm{~W}$ of E2 power. At the same time, a replacement evaporator (evaporator E4) was fabricated. After E4 was integrated into the proto-flight unit, the loop was tested again in the same vacuum chamber for those tests requiring more than $60 \mathrm{~W}$ to E4. In the following discussions, E2 or E4 was clearly labeled in the data plots so there should be no misunderstanding when E2 or E4 was used in a given test.

It should also be noted that the actual loop saturation as indicated by the measured vapor line temperature was always $2 \mathrm{~K}$ higher than the measured CC temperatures. The exact reason for this discrepancy was not known, but could be due to a new CC design that resulted in a thicker layer of liquid formed on the mesh metal attached to the inner wall of the CC. Although this is not a problem in real applications, it is important to keep in mind when examining the test results and analytical model predictions in the following discussions.

Forty three startup tests were conducted with various power profiles to the two evaporators at saturation temperatures between $273 \mathrm{~K}$ and $308 \mathrm{~K}$. All startup tests were successful. Figure 7 shows the loop temperatures in a start-up test where CC1/CC2 temperatures were maintained at 273K/273K prior to start-up. The C1/C2 sinks were kept at $223 \mathrm{~K} / 223 \mathrm{~K}$. As a heat load of $10 \mathrm{~W}$ was applied to E1, the E1 temperature rose gradually. No vapor was generated until the E1 temperature reached $283 \mathrm{~K}$. In other words, a wall superheat of $10 \mathrm{~K}$ was observed at the inception of the start- 
up. Prior to the vapor generation in E1, E2 was at $267 \mathrm{~K}$ even when the E1 temperature was rising because there was no vapor connection between E1 and E2. After the loop had started, however, E2 gradually rose to $273 \mathrm{~K}$ due to heat load sharing between the two evaporators. This test was repeated and similar results were obtained with a superheat of $5.5 \mathrm{~K}$ at the start-up.

Similar start-up phenomena were also observed for start-up at $273 \mathrm{~K}$ when a heat load of $10 \mathrm{~W}$ was applied to E2 only, with a superheat of 8K.

Figure 8 depicts the temperatures in a start-up test where CC1/CC2 temperatures were kept at $273 \mathrm{~K} / 273 \mathrm{~K}$ and a heat load of $50 \mathrm{~W}$ was applied to E2. Initially the loop components were kept at around 264K except for the CCs which were kept at $273 \mathrm{~K}$. When the E2 temperature reached 276K, the loop started with a $3 \mathrm{~K}$ wall superheat. With such a high heat load, not only did the E2 temperature rise quickly during the warm-up period, but E1 also shared heat from E2 soon after the loop started. Figure 9 shows the comparison between analytical model predictions and experimental data for this startup. Because the superheat required for the boiling incipience could not be known in advance, the experimentally observed superheat of $3 \mathrm{~K}$ was used as an input parameter to the analytical model. It is seen that the model predicted all the major events correctly and correlated the critical temperatures (CC and evaporators) within $\pm 5 \mathrm{~K}$ of the experimental results.

LHP start-up with a low power is usually more difficult. The MLHP proto-flight was able to start successfully between $273 \mathrm{~K}$ and $308 \mathrm{~K}$ with heat loads to E1/E2 of $10 \mathrm{~W} / 0 \mathrm{~W}, 0 \mathrm{~W} / 10 \mathrm{~W}$, $5 \mathrm{~W} / 5 \mathrm{~W}, 5 \mathrm{~W} / 0 \mathrm{~W}$, and $0 \mathrm{~W} / 5 \mathrm{~W}$. Figure 10 shows the loop temperatures for a $5 \mathrm{~W} / 0 \mathrm{~W}$ start-up at 293K. Initially, the E1/E2 and vapor line temperatures were below 288K, and CC1/CC2 temperatures were maintained at $293 \mathrm{~K}$ using TECs. As 5W was applied to the E1 thermal mass, the E1 temperature rose gradually. When E1 reached $295 \mathrm{~K}$, the loop started with a $2 \mathrm{~K}$ wall superheat. During the period when E1 was warmed up, the E2 temperature continued to decrease due to the environmental condition. After the loop started, the E2 temperature increased because of heat load sharing. With only 5W to E1, however, the amount of heat that could be shared by E2 was small, and the E2 temperature rose very slowly.

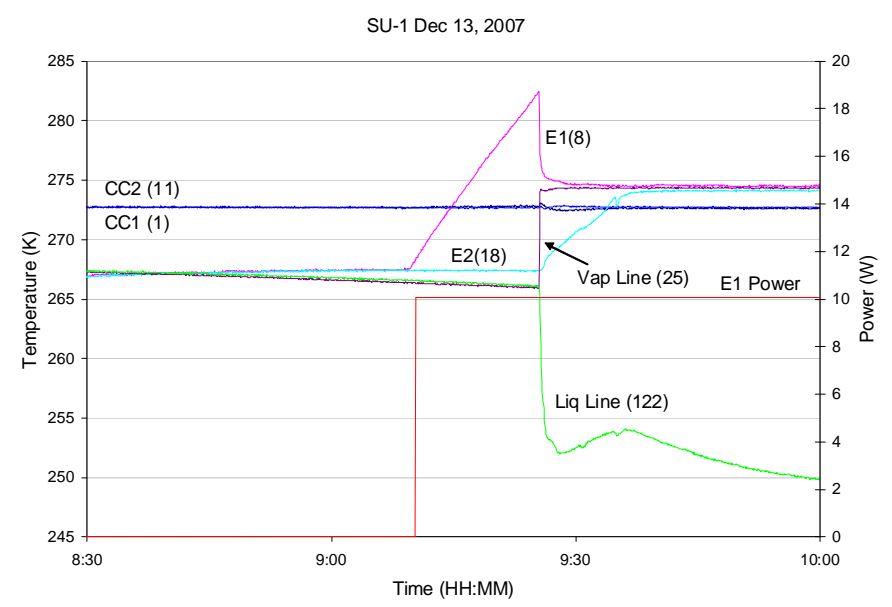

Figure 7. Start-up with $10 \mathrm{~W} / 0 \mathrm{~W}$ at $273 \mathrm{~K}$

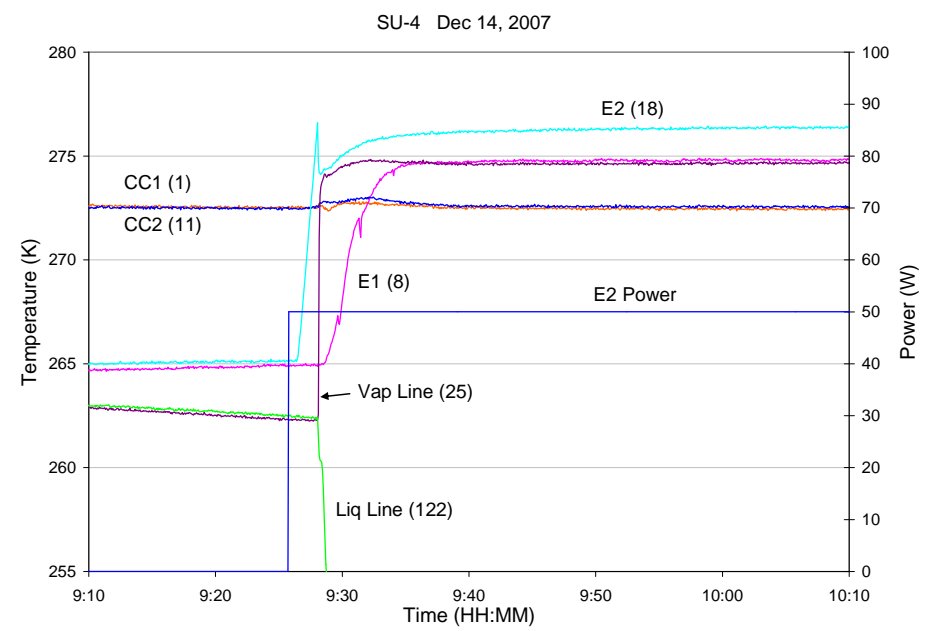

Figure 8. Start-up with $0 \mathrm{~W} / 50 \mathrm{~W}$ at $273 \mathrm{~K}$

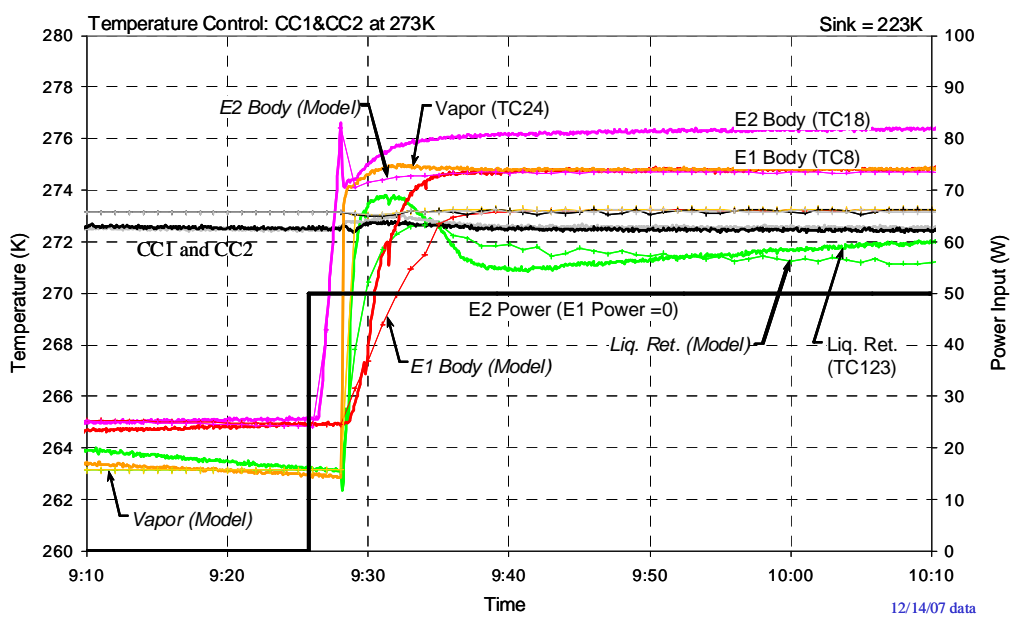

Figure 9. Comparison of Analytical Model Predictions and Experimental Results for Startup with 0 W/50W at 273K 
Figure 11 shows the temperatures of the loop during the start-up at 293K with 5W/5W to E1/E2. Initially, both CC1 and CC2 were kept at $293 \mathrm{~K}$ and E1 and E2 temperatures were below 285K. As 5W was applied to each thermal mass, E1 and E2 temperatures began to rise. Because the E1 thermal mass (540 grams) was almost twice as large as that of E2 (280 grams), the E2 temperature rose at a faster rate than $\mathrm{E} 1$. When the $\mathrm{E} 2$ temperature reached 295.5K, the loop started with a $2.5 \mathrm{~K}$ wall superheat. As mentioned before, with only $5 \mathrm{~W}$ to E2, the vapor generated at E2 moved toward E1 at a very slow rate, and did not appear to contribute to the rise of the E1 temperature. When the E1 temperature rose to $295.2 \mathrm{~K}$ (2.2K wall superheat), vapor was generated in E1. The fact that E1 required a $2.2 \mathrm{~K}$ superheat to generate vapor indicated that vapor generated in E2 had not reached E1 prior to this event, i.e. the E1 evaporator grooves were still flooded with liquid.

Figure 12 shows the loop temperatures during a start-up with a highly uneven heat load of 5W/50W to E1/E2 where TECs were used to keep the CC1/CC2 temperatures at $298 \mathrm{~K}$. When $5 \mathrm{~W} / 50 \mathrm{~W}$ was applied, the E2 temperature rose quickly to $298 \mathrm{~K}$ and vapor was generated in E2 without any superheat. Although the E1 thermal mass was twice that of E2 and received only $5 \mathrm{~W}$ of power, E1 temperatures rose quickly after vapor had been generated in E2 because of the inherent heat load sharing function between the two evaporators and the high heat load of 50W applied to E2. The fact that E1 started without any superheat indicates that E1 had already received vapor from E2 and its vapor grooves had been cleared of liquid. Following the loop start-up, E2 was at a higher temperature than E1 due to the uneven heat load of 5W/50W and the heat transfer requirement.

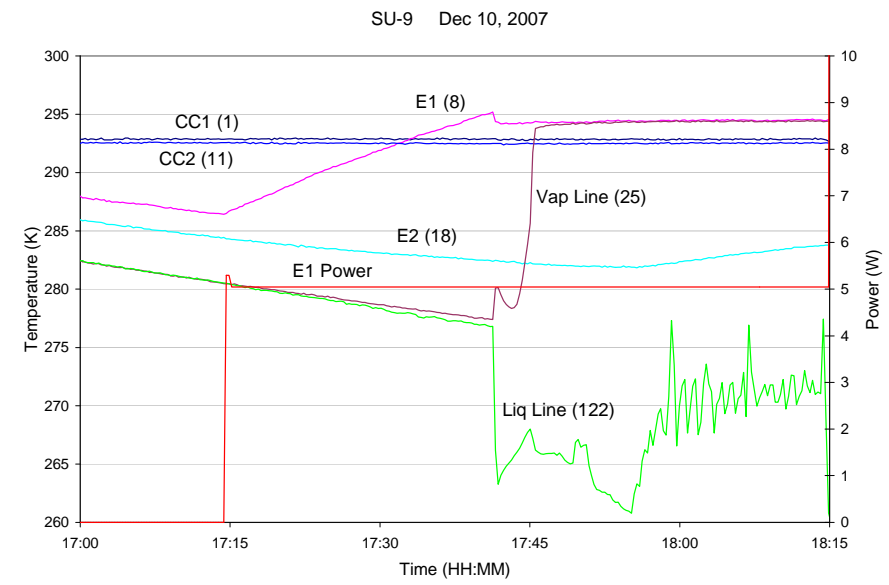

Figure 10. Start-up with 5W/0W at 293K

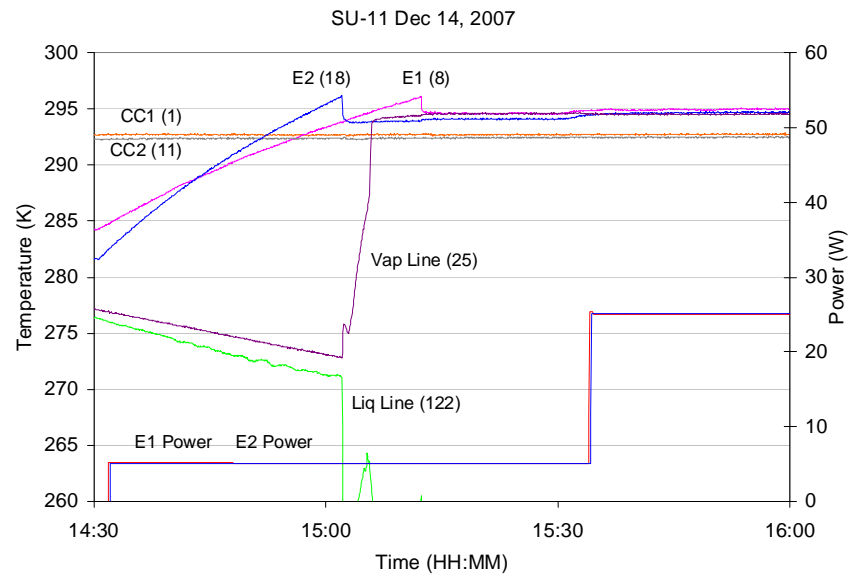

Figure 11. Start-up with 5W/5W at 293K

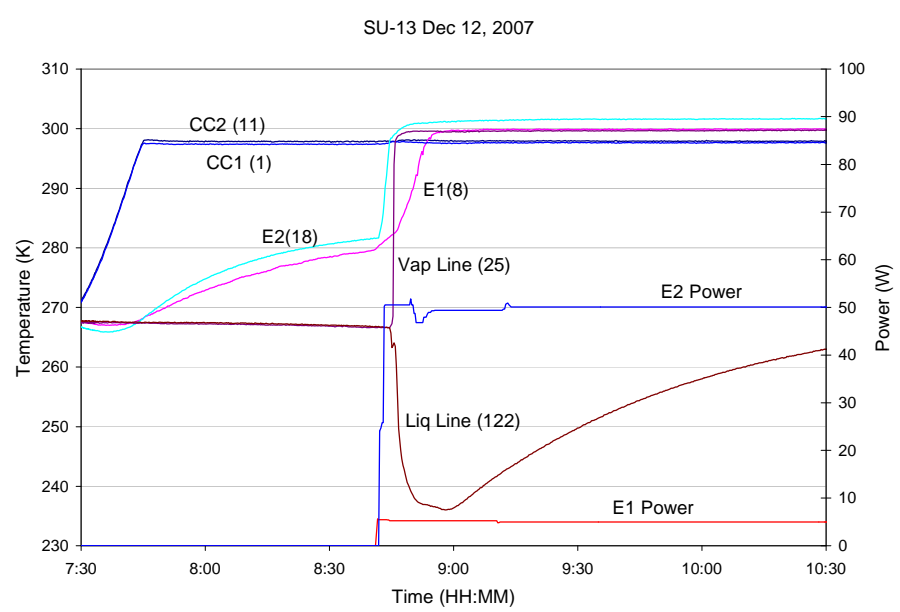

Figure 12. Start-up with $5 \mathrm{~W} / 50 \mathrm{~W}$ at $298 \mathrm{~K}$ 
Several start-up tests were conducted under the sideways configuration where the MLHP proto-flihgt was turned 90 degrees sideways so that CC2/E2 was on a horizontal plane and was above CC1/E1 which was on another horizontal plane. However, the routing of the vapor line formed a three-dimensional geometry so that vapor could not flow directly from E1 to E2 by gravitational force alone. Figure 13 illustrates the loop temperatures for a start-up where the CC temperatures were maintained at $308 \mathrm{~K}$ and a heat load of $10 \mathrm{~W}$ was applied to E2. Also included are temperature profiles in the subsequent power ramp-up test and the analytical model predictions. When the E2 temperature reached 308K, the loop started without a noticeable superheat. In order for the vapor generated in E2 to reach E1, it must overcome the pressure head resulting from the gravity head. At 10W of heat load, the vapor simply could not reach E1. In fact, E1 did not share heat in the subsequent power ramp-up test until the E2 power was increased to 50W. The model predictions of the E1, E2 and vapor line temperatures agreed very well with the experimental data for power up to $50 \mathrm{~W}$. At 60W, E2 (which was damaged) dried out and the LHP model could not predict the loop behavior. During the warm-up period of E2 and its thermal mass, the E2 inlet temperature fluctuated, indicating that some vapor bubbles might be present. Without any knowledge of the fluid state, the model could not predict its behavior. However, once the loop started and liquid began to move, the model predicted the E2 inlet temperature accurately.

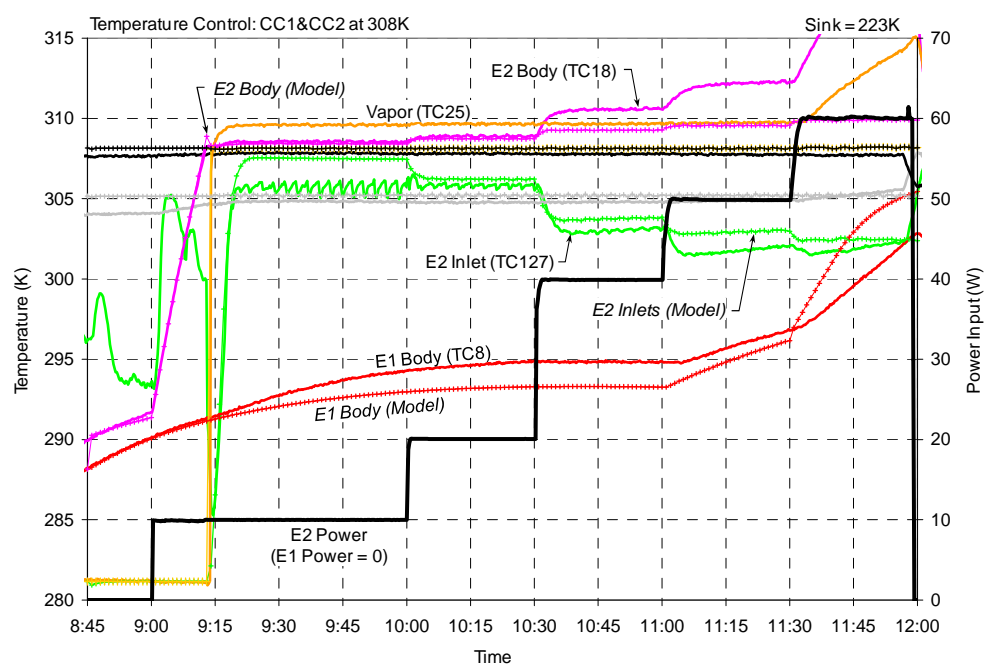

Figure 13. Start-up with $0 \mathrm{~W} / 10 \mathrm{~W}$ at $308 \mathrm{~K}$ and Subsequent Power Ramp-up Tests in Sideways Configuration
Figure 14 shows the loop temperatures for a high power test where the cryopanels were maintained at $173 \mathrm{~K}$ and the temperatures of both CCs were uncontrolled. Even heat loads were applied to E1/E4 from 20W/20W to 70W/70W. Both CC1 and CC2 temperatures varied with the heat loads. Test results showed that CC2 controlled the loop operating temperature and CC1 was hard filled with liquid. The E1 and E4 temperature varied with the CC2 temperature and the heat load. The loop could transport $60 \mathrm{~W} / 60 \mathrm{~W}$ without any problem. At $70 \mathrm{~W} / 70 \mathrm{~W}$, the CC temperatures rose rapidly, an indication that vapor has penetrated the evaporator wick, i.e. the loop had exceeded its capillary limit.

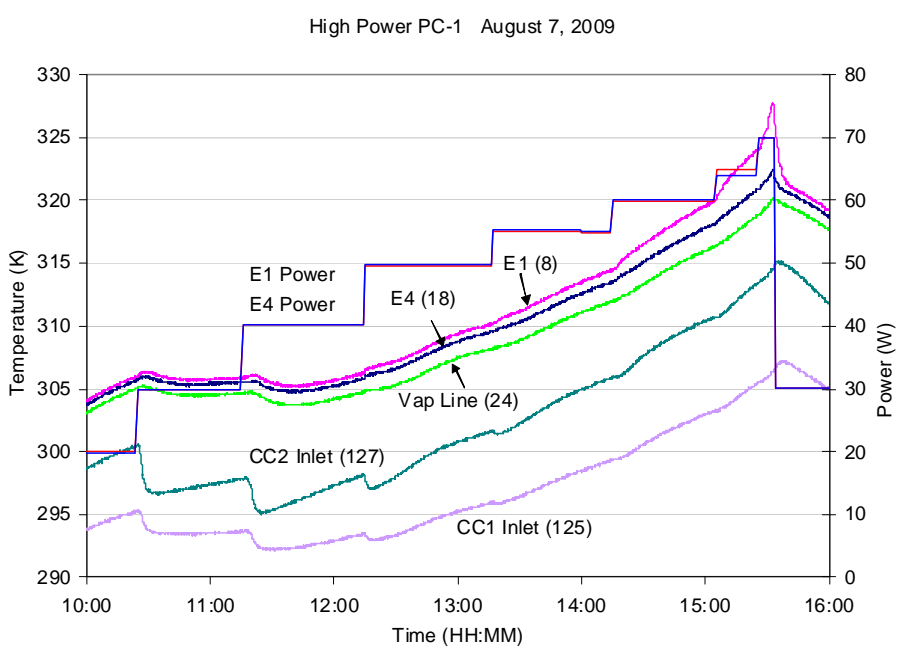

Figure 14. High Power Test without CC Temperature Control

Figure 15 shows loop temperatures during a power cycle test where both CCs were kept at 308K by the TECs and the cryopanels were maintained at $173 \mathrm{~K}$. The heat load to E1/E4 was varied as follows: $75 \mathrm{~W} / 0 \mathrm{~W}, 50 \mathrm{~W} / 25 \mathrm{~W}$, 25W/50W, 0W/75W, 5W/50W, 50W/5W, 50W/50W, and 60W/60W. Despite some large variations in the heat load, the TECs were able to control both CC temperatures at the set point temperature of 308K. The temperatures of E1 and E4 varied with the heat load to each individual evaporator due to the heat transfer requirement. This test also demonstrated once again that the loop could transport up to $120 \mathrm{~W}$ of total heat load (60W/60W to E1/E4). 
Figure 16 shows the loop temperatures where the temperatures of Radiator 1 and Radiator 2 were varied independently by setting their control heaters at different set point temperatures. Both CC1 and CC2 were controlled at 293K by TECs, and an uneven heat load of 30W/10W was applied to the E1/E2 thermal masses. The set point temperatures of control heaters for Radiator 1/Radiator 2 were varied as follows: 223K/223K, 298K/223K, $\quad 303 \mathrm{~K} / 223 \mathrm{~K}, \quad 223 \mathrm{~K} / 223 \mathrm{~K}$, $223 \mathrm{~K} / 298 \mathrm{~K}, 223 \mathrm{~K} / 303 \mathrm{~K}$, and $223 \mathrm{~K} / 223 \mathrm{~K}$. The CC1/CC2 temperatures were maintained within $\pm 1 \mathrm{~K}$ of the set point temperature and E1 and E2 temperatures were unaffected by the radiator temperature variations. The flow regulator automatically balanced the heat dissipations between the two condensers. When the temperature of one radiator was raised above the CC saturation temperature, the flow regulator was able to prevent the vapor from entering the liquid line throughout the test as evidenced by the subcooled temperature of the liquid line immediately downstream of the condensers (TC119).

Figure 17 shows the loop temperatures for another radiator temperature cycle test where an uneven heat load of 5W/50W was applied to E1/E2 and both CCs were maintained at 298K using TECs. The control heater set points for Radiator 1/Radiator 2 were varied as follows: $223 \mathrm{~K} / 223 \mathrm{~K}$, 243K/223K, 298K/223K, 303K/223K, 223K/223K, 223K/303K, and 223K/223K. Again, the E1 and E2 temperatures were unaffected by the changes in the radiator temperatures. When the temperature of one of the radiators was raised higher than the loop saturation temperature, the flow regulator was able to redistribute the vapor between the two condensers and prevent the vapor from entering the liquid line.

The ability of the CC to control the loop operating temperature when the heat load distribution between the evaporators or when the condenser sink temperatures varied have been shown in Figures 15 to 17 . Several tests were also performed to demonstrate that the loop operating temperature itself could be varied and the loop still performed smoothly during the transitions. Figure 18 depicts loop temperatures during a CC set point change test. In the first part of the test, a heat load of 52W/5W was applied to E1/E2 thermal masses (or instrument simulators, "IS1" or "IS2" on the figure). The temperature inside the thermal vacuum chamber surrounding the evaporators/CCs,

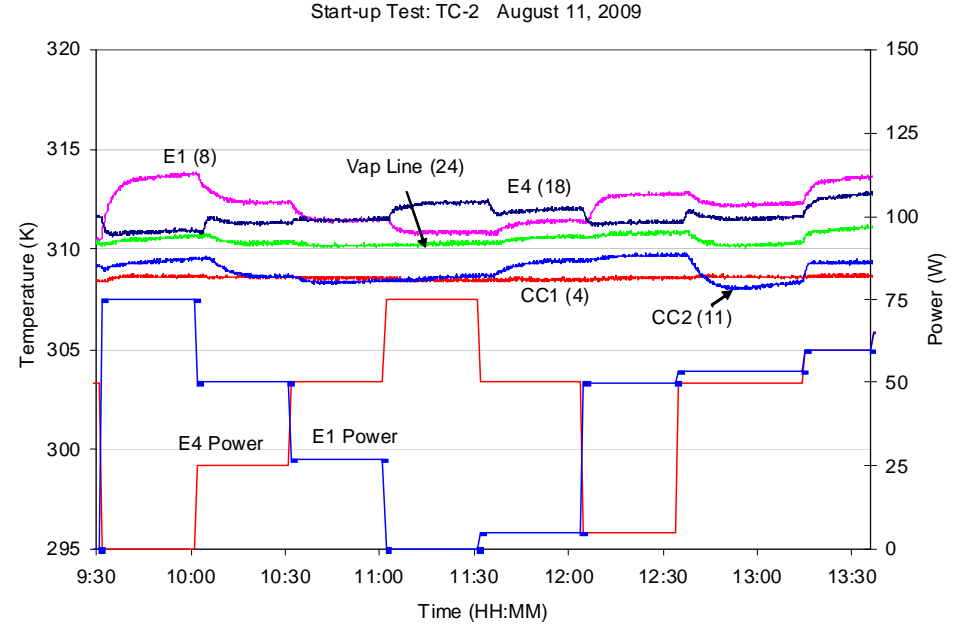

Figure 15. Power Cycle Test with Uneven Power at 308K

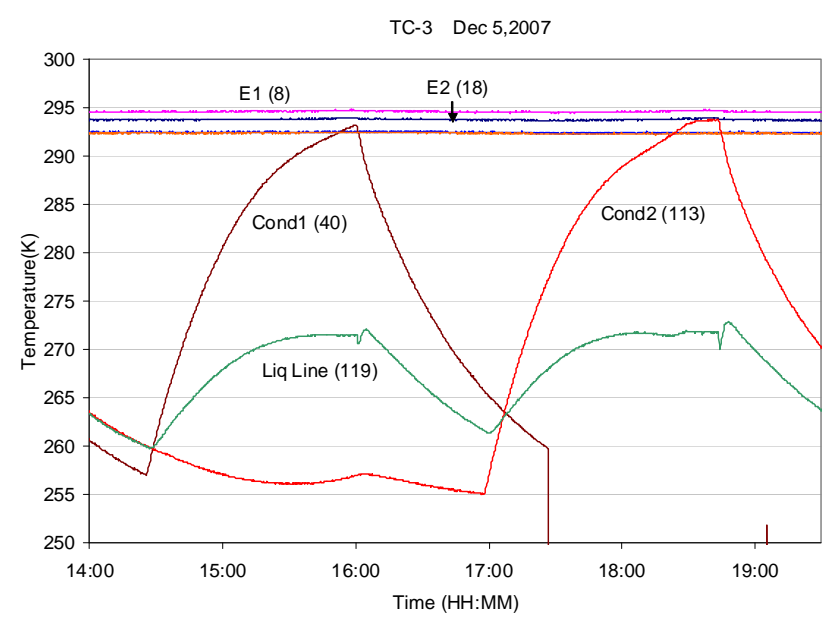

Figure 16. Flow Regulation Test with Uneven Power at 293K

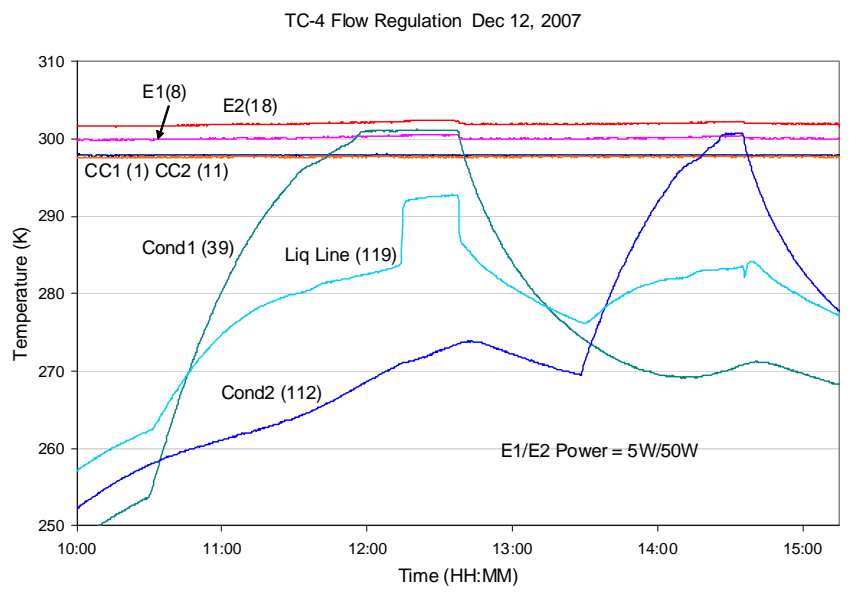

Figure 17. Sink Temperature Cycle Test with Uneven Power at $298 \mathrm{~K}$

10

American Institute of Aeronautics and Astronautics 
thermal masses, vapor line, and liquid line, was about 283K. The TECs were able to keep both CCs at 273K. The temperatures of both CCs were then raised from $273 \mathrm{~K}$ to $298 \mathrm{~K}$ in steps with $5 \mathrm{~K}$ increments. Temperatures of E1, E2 and their thermal masses rose in tandem with the CC temperature rise. In the second part of the test, a heat load of 5W/50W was applied to E1/E2 thermal masses. The temperatures of both CCs were decreased in steps with $5 \mathrm{~K}$ increments. Again, temperatures of E1, E2 and their thermal masses decreased with the CC temperatures. This test demonstrated the ability of the CCs to control the loop operating temperature when the temperatures of the CCs were changed.

For typical heat load sharing tests designed to demonstrate the ability of the unpowered evaporator to share heat from the powered evaporator, some active cooling method is provided to the unpowered evaporator or its attached thermal mass so that the amount of heat that is shared can be quantitatively determined. The MLHP proto-flight was intended for a space flight demonstration and no active cooling was incorporated in its design. Nevertheless, the heat load sharing function can still verified qualitatively by applying power to one of the evaporator thermal masses and then raising the CC set point temperature in steps. If temperatures of the un-powered evaporator/thermal mass also rise near the newly set CC temperature, one can infer that the heat source comes from the vapor generated by the powered evaporator, thus demonstrating the heat load sharing function.

Figure 19 shows the results of a heat load sharing test where a heat load of $30 \mathrm{~W}$ was applied to E2, and the CC2 set point temperature was increased from $273 \mathrm{~K}$ to $313 \mathrm{~K}$ in steps with $5 \mathrm{~K}$ increments. As the CC2 temperature increased, not only did the powered evaporator E2 and its instrument simulator rise in temperature accordingly, but the unpowered evaporator E1 and its thermal mass also rose to near the CC2 temperature.

Figure 20 shows the temperatures in a heat load sharing test where a heat load of $30 \mathrm{~W}$ was applied to E1. The test was a mirror image of test shown in Figure 19, and similar results were obtained. Also shown in the

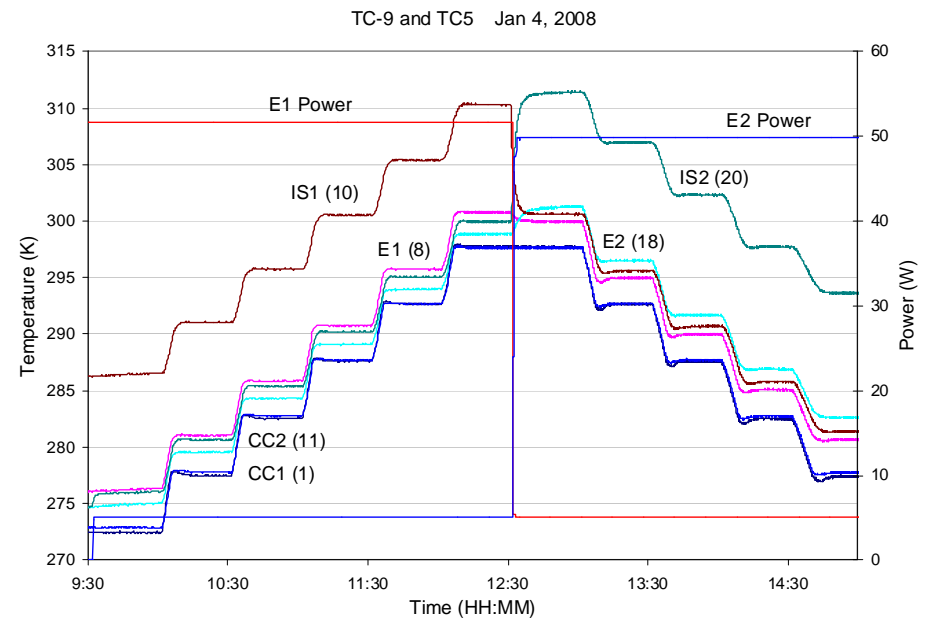

Figure 18. CC Set Point Change Test

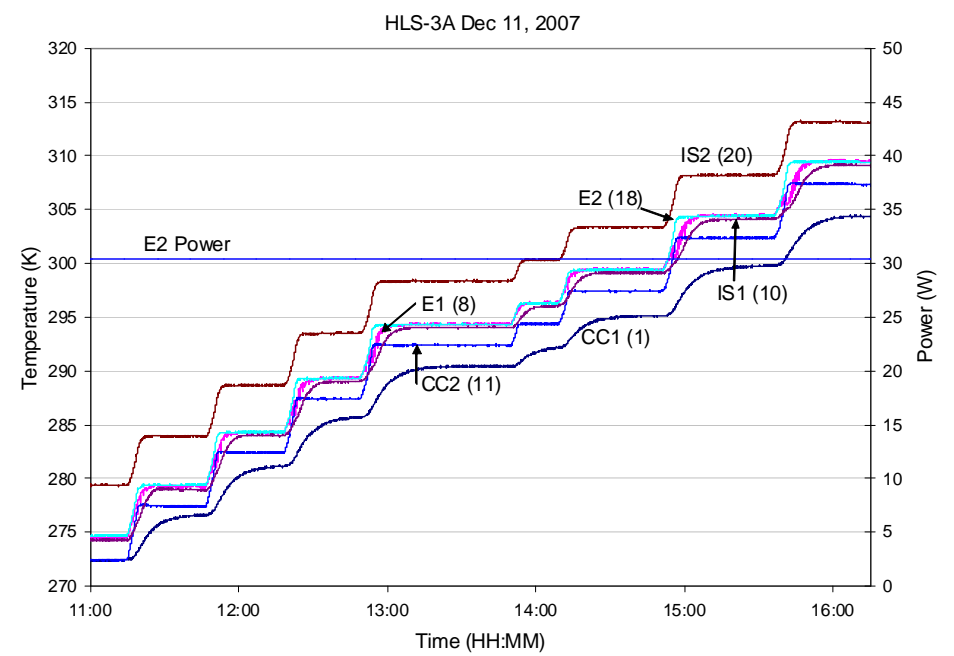

Figure 19. Heat Load Sharing Test

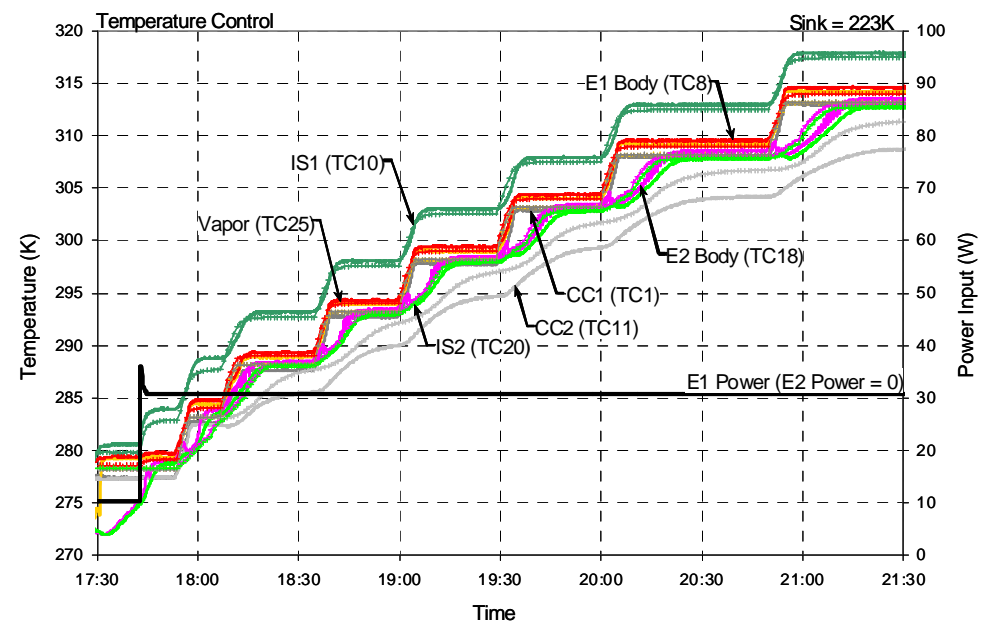

Figure 20. Comparison of Analytical Model Predictions (Thin Lines) and Experimental Data (thick Lines) of a Heat Load Sharing Test

11

American Institute of Aeronautics and Astronautics 
figure are the analytical model predictions of the temperatures of the CCs, evaporators, and thermal masses. The model predictions were in excellent agreement with the experimental data.

Figure 21 depicts another heat load sharing test where E2 received 50W and E1 was unpowered. The CC2 temperature was increased from $298 \mathrm{~K}$ to $313 \mathrm{~K}$ and then decreased from $313 \mathrm{~K}$ to $298 \mathrm{~K}$ with $5 \mathrm{~K}$ increments. It is seen that the temperatures of $\mathrm{E} 1$ and its thermal mass increased with an increasing CC2 temperature, indicating that E1 worked as a condenser and shared heat from E2. When the CC2 temperature was decreasing, both E1 and its thermal mass also decreased in temperature, indicating that E1 switched its operation back to the normal evaporator mode and dissipated heat that was stored in its thermal mass. This test illustrated that the evaporator would switch its operation automatically between the condenser and evaporator modes as the thermal condition of its surrounding environment changed.

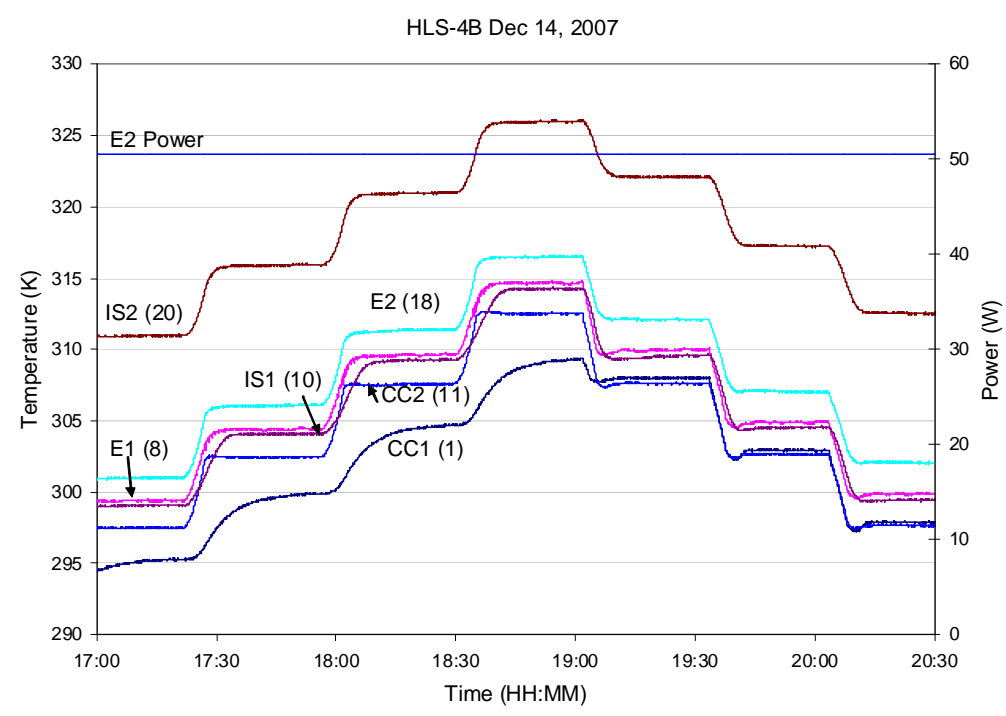

Figure 21. Heat Load Sharing Test

\section{Conclusion}

The MLHP proto-flight unit demonstrated excellent performance in the thermal vacuum test. The loop started successfully and operated stably under various evaporator heat loads and condenser sink temperatures. The TECs could keep the loop operating temperature within $\pm 1 \mathrm{~K}$ of the desired set point temperature at all power levels and all sink temperatures. The un-powered evaporator automatically drew heat from the other powered evaporator, demonstrating the heat load sharing function. The flow regulators could regulate the heat dissipation among the radiators, and prevent vapor from entering the liquid line when one of the condensers exhausted its heat dissipating capability. Predictions of the LHP analytical model agreed very well with experimental data in all cases that were correlated. All of the success criteria were met or exceeded.

\section{Acknowledgments}

Funding for this investigation was provided by the NASA New Millennium Program. The MLHP Breadboard and proto-flight unit were manufactured by ATK Space Systems in Beltsville, Maryland. The authors would like to thank the Thermal Loop experiment Technology Review Board members - John Stocky, Charles Minning, Eugene Ungar, James Yuko, Mel Bello, and Jay Ochterbeck - for their valuable suggestions during the course of this study.

\section{References}

1. Maidanik, Y., and Fershtater, Y., “Theoretical Basis and Classification of Loop Heat Pipes and Capillary Pumped Loops,” $10^{\text {th }}$ International Heat Pipe Conference, Stuttgart, Germany, 1997.

2. Ku, J., “Operating Characteristics of Loop Heat Pipes,” SAE Paper No. 1999-01-2007, $29^{\text {th }}$ International Conference on Environmental Systems, Denver, Colorado, July 12-15, 1999.

3. Baker, C., Butler, D., Ku, J., and Grob, E., "Acceptance Thermal Vacuum Tests of the GLAS Flight Loop Heat Pipe Systems,” Space Technology and Applications International Forum -2001, Albuquerque, New Mexico, February 11-14, 2001.

4. Baker, C and Grob, E., "System Accommodation of Propylene Loop Heat Pipes for The Geoscience Laser Altimeter System (GLAS) Instrument,” SAE Paper No. 2001-01-2263, 31 $1^{\text {st }}$ International Conference on Environmental Systems, Orlando, Florida, July 9-12, 2001. 
5. Grob, E., Baker, C., and McCarthy, T., "Geoscience Laser Altimeter System (GLAS) Loop Heat Pipe: An Eventful first Year On-Orbit”, Paper No. 2004-01-2558, 34 ${ }^{\text {th }}$ International Conference on Environmental Systems, Colorado Springs, Colorado, July 19-22, 2004.

6. Ottenstein, L., Ku, J., and Feenan, D., "Thermal Vacuum Testing of a Novel Loop Heat Pipe Design for the Swift BAT Instrument," Space Technology and Applications International Forum -2003, Albuquerque, New Mexico, February 2-6, 2003.

7. Choi, M., "Swift BAT Loop Heat Pipe Thermal System Characteristics and Ground/Flight Operation Procedure,” Paper No.

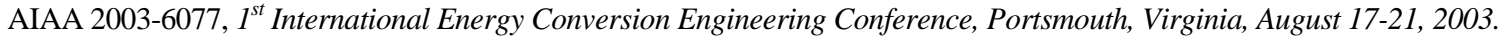

8. Choi, M., “Thermal Vacuum/Balance Test Results of Swift BAT with Loop Heat Pipe Thermal System”, AIAA Paper No. 20045683, $2^{\text {nd }}$ International Energy Conversion Engineering Conference, Providence, Rhode Island, August 16-19, 2004.

9. Choi, M., “Thermal Assessment of Swift BAT Instrument Thermal Control System In Flight”, Paper No. 2005-01-3037, 35 ${ }^{\text {th }}$ International Conference on Environmental Systems, Rome, Italy, July 11-14, 2005.

10. Rodriguez, J. I., Na-Nakornpanom, A., Rivera, J., Mireles, V. and Tseng, H., "On-Orbit Thermal Performance of the TES Instrument - Three Years in Space,” SAE Paper No. 2008-01-2118, 38 ${ }^{\text {th }}$ International Conference on Environmental Systems, San Francisco, California June 30 - July 2, 2008.

11. Nikitkin, M. and Wolf, D., "Development of LHP with Low Control Power," Paper No. 2007-01-3237, 37 ${ }^{\text {th }}$ International Conference on Environmental Systems, Chicago, Illinois, July 9-12, 2007.

12. Ku, J., "Heat Load Sharing in a Loop Heat Pipe with Multiple Evaporators and Multiple Condensers," AIAA Paper No. AIAA-2006-3108, $9^{\text {th }}$ AIAA/ASME Joint Themophysics and Heat Transfer Conference, San Francisco, California, June 5-8, 2006.

13. Ku, J., Ottenstein, L., and Birur, G., “Thermal Performance of a Multi-Evaporator Loop Heat Pipe with Thermal Masses and Thermoelectric Coolers", $13^{\text {th }}$ International Heat Pipe Conference, Shanghai, China, September 21-25, 2004.

14. Ku, J. and Nagano, H., "Using Thermoelectric Converters for Loop Heat Pipe Operating Temperature Control,” AIAA Paper No. AIAA-2006-4057, $4^{\text {th }}$ Intersociety Energy Conversion Engineering Conference, San Diego, California, June 2629, 2006.

15. Ku, J. and Nagano, H., “Loop Heat Pipe Operation with Thermoelectric Converters and Coupling Blocks,” AIAA Paper No. AIAA-2007-4713, $5^{\text {th }}$ Intersociety Energy Conversion Engineering Conference, St. Louis, Missouri, June 25-27, 2007.

16. Nagano, H. and Ku, J., "Capillary Limit of a Miniature Loop Heat Pipe with Multiple Evaporators and Multiple Condensers,” AIAA Paper No. AIAA-2006-3110, $4^{\text {th }}$ International Energy Conversion Engineering Conference, San Diego, California, June 26-29, 2006.

17. Nagano, H. and Ku, J., "Gravity Effect on Capillary Limit of a Miniature Loop Heat Pipe with Multiple Evaporators and Multiple condensers," Space Technology and Applications International Forum -2007, Albuquerque, New Mexico, February 11-15, 2007.

18. Ku, J., Ottenstein, L., Butler, D. and Nagano, H., "Thermal Performance of a Miniature Loop Heat Pipe with Multiple Evaporators and Multiple Condensers,“ $14^{\text {th }}$ International Heat Pipe Conference, Florianópolis, Brazil, April 22-27, 2007.

19. Ku, J., Ottenstein, L., and Nagano, H., "Thermal Vacuum Testing of a Miniature Loop Heat Pipe with Multiple Evaporators and Multiple Condensers,“ Paper No. HT2007-32302, 2007 ASME/JSME Thermal Engineering Summer Heat Transfer Conference, Vancouver, British Columbia, Canada, July 8-12, 2007.

20. Ku, J. and Nagano, H., "Effects of Gravity on Start-up and Heat Load Sharing of a Miniature Loop Heat Pipe,” Paper No. 2007-01-3234, 37 ${ }^{\text {th }}$ International Conference on Environmental Systems, Chicago, Illinois, July 9-12, 2007.

21. Ku, J., Hoang, T., and O’Connell, T., "Mathematical Modeling of a Miniature Loop Heat Pipe with Two Evaporators and Two Condensers,” Paper No. HT2009-88243, 2009 ASME Summer Heat Transfer Conference, San Francisco, California, July 19-23, 2009. 